\title{
SMOKING AND THE USE OF THE HEALTH SERVICES
}

\author{
J. R. ASHFORD
}

University of Exeter

During recent years very wide interest has been shown in the relation between smoking habits and health, and the literature has been well summarized in the publication Smoking and Health Now by the Royal College of Physicians (1971). For the most part emphasis has been given to the effect of smoking habits on the shortening of life and it has been estimated that in the United Kingdom two smokers out of every five are likely to die before reaching the age of 65 years, as opposed to only one out of five non-smokers. However, death is often the final stage of a protracted disease process and morbidity may then be an even more sensitive indicator of impairment of health than mortality. Although the effect of smoking on morbidity has been studied in a wide variety of circumstances the approach most commonly adopted has been to carry out a special survey of a specific population involving a standard examination or enquiry. For example, studies of coal miners in the United Kingdom (Ashford, Brown, Morgan, and Rae, 1968; Ashford, Morgan, Rae, and Sowden, 1970) have shown that smoking is associated with impairment of ventilatory function, with an increase of respiratory symptoms, and with absence from work due to chest illness. In contrast, the present study is concerned with the use made of the health services by a large community over a substantial period of time.

The Exeter Community Health Research Project has been described by Ashford and Pearson (1970). This project involved a study of morbidity in the City of Exeter during the calendar year November 1966-October 1967. For a population consisting at any one time of some 70,000 persons defined by the National Health Service general practice lists of about three-quarters of the general practitioners then working in the city, a record was made of each general practice surgery attendance, general practice home visit, hospital outpatient attendance, and hospital inpatient stay. In order to obtain information about the personal characteristics of the survey population a private census was undertaken. This census included a record of individual smoking habits and it was thus possible to examine the relation between smoking and the use made of the local health services in that section of the population for which both sources of information are available.

\section{METHODOLOGY}

A detailed description of the population examined, the survey techniques, the content of the data collected, and the methods of analysis has been given by Ashford and Pearson (1970) and the following is a brief summary of those aspects which are directly relevant to the present study. At the time of the morbidity survey, the population of the City of Exeter consisted of some 90,000 persons. The morbidity survey was confined to the registered NHS patients of 35 (out of 49) general practitionerso In all, some 75,500 patients were involved, of whong about 63,500 were registered throughout the whole survey year, about 6,500 joined the population about 5,250 left the population, and about 300 both joined and left the population during that period. The age and sex distributions of the survey population agree closely with the corresponding data for the City of Exeter collected in the 1966 Sample Census.

In order to supplement the somewhat meagre personal information available from the general practice records, a special enquiry was mounted. A census of the whole population living within the City of Exeter was therefore undertaken. Each address was visited by a trained interviewer who put a standard series of questions to a responsible member of each household concerned. In the event, contact was made with about three-quarters of the households, no reply being obtained from the remainder in spite of up to four 'calls-back' during the eight-week period of the census. About oneeighth of the households refused to cooperate. As a result, the census information was collected about some 53,500 persons, representing about fiveeighths of the morbidity survey population and a similar proportion of households in the city. The distribution of household attributes was compared with the corresponding data for the 1966 Sample Census. In general, agreement was reasonably good, although there was an undersampling of households 
containing more than six rooms. The distribution of individuals covered in the census in terms of age, sex, and marital status shows only minor discrepancies with the 1966 Sample Census, the main feature being a slight under-representation of elderly women.

A total of 32,219 persons included in the morbidity survey were also covered in the census and the present study is concerned with this particular population. The reported use of the health services by the group was compared with that of the remainder of the morbidity survey population and the results were in close agreement. On this basis and in view of the generally good agreement with the 1966 Sample Census, it is considered that the population covered on both the morbidity survey and the census is reasonably representative of the City of Exeter as a whole. In particular, there is no apparent reason why any relationships which may exist within this group between smoking habits and the use of the health services should not apply to the larger population.

As part of the morbidity survey, a record was made of each patient contact in general practice and with the $\mathbf{4 4}$ local hospitals which provide virtually the whole of the hospital services enjoyed by Exeter residents. Each record included information about the date and type of contact and the diagnoses or main symptoms involved. Thus, general practice contacts were classified in terms of surgery attendances and home visits and hospital contacts in terms of outpatient attendances and inpatient stays. The information about inpatient stays also includes the duration. The diagnostic information was subsequently coded using the ICD Classification (World Health Organization, 1957), with certain supplementary categories. Bearing in mind the qualifications which must inevitably be made about diagnostic information of this kind, the classification at least in terms of the ICD 'broad diagnostic' categories is regarded as reasonably reliable.

The census included questions about the smoking habits of each member of the household concerned, which were compiled using the same form of enquiry as that recommended by the Medical Research Council Committee on the Aetiology of Chronic Bronchitis (Medical Research Council, 1961). For the most part the information collected referred to current smoking habits and each smoker was classified according to depth of inhalation and consumption of manufactured cigarettes, handrolled cigarettes, pipe tobacco, small cigars, and large cigars. Past smoking habits were involved only in terms of whether the subject had ever smoked and, if so, the age of starting to smoke. The criterion for classification as a smoker was that the subject was currently smoking the equivalent of one cigarette per day and as an ex-smoker that the subject had in the past smoked as much as one cigarette per day (or the equivalent quantity of tobacco in other ways) for as long as one year but did not smoke at the time of the survey. This concentration on current smoking habits reflects the unreliability of detailed statements about past smoking habits, which, coupled with the fact that substantial changes in smoking habits are not uncommon, militates against the construction of a reliable and detailed cumulative smoking history (Todd, 1966).

The accuracy and completeness of the data about the use of the health services have been assessed. In general it is considered that the amount of underrecording of patient contacts in both general practice and hospital is likely to have been small and the relatively meagre information collected about each contact is likely to be reasonably accurate. As far as the census is concerned, comparison of the results obtained on the pilot and main censuses for about 1,000 individuals showed, in general, a high level of consistency. It must be emphasized that the information about personal smoking habits was collected from a single individual in each household. The respondent was almost invariably a close relative of, or very well known to, each of the other members of the same household, but if there was any uncertainty about a particular part of the smoking history the item was classified as 'unknown'. When the reported smoking habits of the respondents and non-respondents were compared no consistent differences were recorded. This conclusion is consistent with the work of Todd (1966), who reported that 'recalls made by relatives would appear to be a reasonably accurate substitute, in respect of both types of tobacco products and amounts smoked, for recalls by the informants themselves in that the inaccuracies of the two groups were largely and about equally compensating'.

The population upon which the present study is based consists of those persons included in the morbidity survey for whom information about smoking habits was obtained on the census. Some of this group joined the population after the start of the morbidity survey and others left the population before the end of the morbidity survey. Thus, while the great majority were 'at risk' for the whole calendar year, others were registered with the Exeter general practitioners taking part in the survey for shorter periods. In the analysis of the use of the health services to be described subsequently, 
TABLE I

DISTRIBUTION OF SMOKING HABITS AMINED IN BOTH MORBIDITY SURVEY AND CENSUS NUMBERS OF PERSON/YEARS AT RISK

\begin{tabular}{|c|c|c|c|c|c|c|c|c|c|c|}
\hline & & & \multicolumn{8}{|c|}{ Smoking Habits } \\
\hline \multirow{2}{*}{\multicolumn{3}{|c|}{$\begin{array}{l}\text { Age Group } \\
\text { (years) }\end{array}$}} & \multicolumn{2}{|c|}{ Smọers } & \multicolumn{2}{|c|}{ Non-smokers } & \multicolumn{2}{|c|}{ Ex-smokers } & \multicolumn{2}{|c|}{ All } \\
\hline & & & Males & Females & Males & Females & Males & Females & Males & Females \\
\hline $\begin{array}{l}\text { Under } 15 \\
15-29 \\
30-44 \\
45-59 \\
\text { Over } 59 \\
\text { Unknown }\end{array}$ & $\begin{array}{l}\cdots \\
\cdots \\
\cdots \\
\cdots \\
\cdots\end{array}$ & $\begin{array}{l}\cdots \\
\cdots \\
\cdots \\
\cdots \\
\cdots\end{array}$ & $\begin{array}{r}7 \\
1,122 \\
1,689 \\
1,693 \\
1,220 \\
17\end{array}$ & $\begin{array}{r}9 \overline{912} \\
1,264 \\
1,163 \\
632 \\
10\end{array}$ & $\begin{array}{r}4,112 \\
1,427 \\
847 \\
674 \\
575 \\
5\end{array}$ & $\begin{array}{r}3,928 \\
2,112 \\
1,805 \\
1,592 \\
2,446 \\
24\end{array}$ & $\begin{array}{r}\overline{66} \\
262 \\
396 \\
465 \\
2\end{array}$ & $\begin{array}{r}\overline{75} \\
190 \\
204 \\
216 \\
2\end{array}$ & $\begin{array}{r}4,119 \\
2,615 \\
2,798 \\
2,763 \\
2,260 \\
24\end{array}$ & $\begin{array}{r}3,928 \\
3,099 \\
3,259 \\
2,959 \\
3,294 \\
36\end{array}$ \\
\hline Total & .. & . & 5,748 & 3,981 & 7,640 & 11,907 & 1,191 & 687 & 14,579 & 16,575 \\
\hline
\end{tabular}

due account is taken of variations in time at risk. The distribution of the population in terms of age and current smoking habits (where ascertained) is summarized in Table I, which shows the numbers of 'person/years' at risk. In this Table one person/year corresponds to one person registered for the whole year or two persons each registered for six months or three persons each registered for four months and so on. In all, 31,000 person/years of risk are covered, of which about 9,750 refer to smokers, 19,500 to non-smokers, and 1,850 to ex-smokers. The numbers of person/years in each of the five-year age groups vary from about 200 to about 500 for both males and females in the 15-69 years range. The ex-smokers represent a considerably smaller total period at risk than either of the other groups.

The distribution of current smoking habits was analysed in terms of age and sex. In males the proportion of smokers increases with age to a maximum of about 600 per 1,000 for the 25-64 years age-groups and subsequently declines with increasing age. The proportion of ex-smokers increases steadily with age and reaches a maximum of about 200 per 1,000 in the oldest groups. The average depth of inhalation tends to decrease with increasing age. In the under 60 years age-groups almost half the smokers inhale moderately, but in the older age-groups the majority of current smokers do not inhale. The proportions of female smokers and their average depth of inhalation are considerably lower than the corresponding figures for males of the same age, particularly in the older section of the population. About 1 in 10 of the males started to smoke at less than 16 years of age and a slightly smaller proportion started to smoke at 16 years of age. The females have a higher average age of starting smoking, coupled with a tendency for the age of starting to increase with increasing age of the subject. The majority of smokers consume manufactured cigarettes only and only a small proportion smoke rolled cigarettes only or pipeonly. The variation of smoking habits was alsoco analysed in terms of a range of personal character -0 istics. The most well-defined relationship is that with social class, the proportion of both male and female smokers showing a marked tendency too increase with decreasing social class. Among males the maximum proportions of smokers vary from $\bar{k}$ just over $40 \%$ in social class 1 to about $80 \%$ in $\overrightarrow{0}$ social class 5 . The corresponding figures for fematest are about $30 \%$ and about $60 \%$. The amount of tobacco consumed and the depth of inhalation temdo to decrease with increasing social class, whereas theage of starting smoking tends to increase. The various aspects of personal smoking habits are tof some extent confounded, in the sense that the group? who started smoking at the earlier ages tend also too inhale more deeply and, for smokers of manufactured cigarettes only, to consume a greater amount of tobacco than the remainder. This is, of course, a. reflection of the fact that the allocation of smoking habits to particular subjects is uncontrolled, in the? sense that an individual's smoking history is a윽 reflection of personal circumstances, environment and inclination. Moreover, it is not possible to assess? each particular aspect of smoking habits separately, as when the population of smokers is subdivided? into the required multiple categories in this way the total exposure covered by a particular categoryㅡ. becomes too small to permit reliable conclusions to be obtained.

\section{General Practice Contacts}

The main types of patient contact with the healtho services are attendances at a general practice surgery and home visits. The contact rates have been ${ }^{+}$ found to vary with age and sex. For this reason the populations of males and females were subdivided? 
TABLE II

AVERAGE NUMBERS OF GENERAL PRACTICE CONTACTS IN TERMS OF SMOKING HABITS

\begin{tabular}{|c|c|c|c|c|c|c|c|c|c|c|c|c|c|c|c|c|c|}
\hline & & \multicolumn{8}{|c|}{ (a) Males } & \multicolumn{8}{|c|}{ (b) Females } \\
\hline & & \multicolumn{4}{|c|}{ Surgery Attendances } & \multicolumn{4}{|c|}{ Home Visits } & \multicolumn{4}{|c|}{ Surgery Attendances } & \multicolumn{4}{|c|}{ Home Visits } \\
\hline \multicolumn{2}{|c|}{ Age Group (yr) } & $\begin{array}{l}15- \\
29\end{array}$ & $\begin{array}{l}30- \\
44\end{array}$ & $\begin{array}{l}45- \\
59\end{array}$ & $\underset{59}{\text { Over }}$ & $\begin{array}{l}15- \\
29\end{array}$ & $\begin{array}{l}30- \\
44\end{array}$ & $\begin{array}{l}45- \\
59\end{array}$ & $\underset{59}{\text { Over }}$ & $\begin{array}{l}15- \\
29\end{array}$ & $\begin{array}{l}30- \\
44\end{array}$ & $\begin{array}{l}45- \\
59\end{array}$ & $\underset{59}{\text { Over }}$ & $\begin{array}{l}15- \\
29\end{array}$ & $\begin{array}{l}30- \\
44\end{array}$ & $\begin{array}{c}45- \\
59\end{array}$ & $\underset{59}{\text { Over }}$ \\
\hline $\begin{array}{l}\text { All } \\
\text { patients }\end{array}$ & $\begin{array}{l}\text { Smokers } \\
\text { Non-smokers } \ldots \\
\text { Ex-smokers } \quad \cdots\end{array}$ & $\begin{array}{l}1 \cdot 9 \\
1 \cdot 6 \\
2 \cdot 1\end{array}$ & $\begin{array}{l}2 \cdot 2 \\
1 \cdot 5 \\
1 \cdot 8\end{array}$ & $\begin{array}{l}2 \cdot 3 \\
2 \cdot 0 \\
2 \cdot 0\end{array}$ & $\begin{array}{l}2 \cdot 3 \\
2 \cdot 9 \\
2 \cdot 8\end{array}$ & $\begin{array}{l}0 \cdot 21 \\
0 \cdot 17 \\
0 \cdot 28\end{array}$ & $\begin{array}{l}0 \cdot 28 \\
0 \cdot 18 \\
0 \cdot 28\end{array}$ & $\begin{array}{l}0.43 \\
0.33 \\
0.46\end{array}$ & $\begin{array}{l}1 \cdot 4 \\
2 \cdot 3 \\
2 \cdot 1\end{array}$ & $\begin{array}{l}4 \cdot 1 \\
3 \cdot 4 \\
7 \cdot 1\end{array}$ & $\begin{array}{l}3 \cdot 1 \\
2 \cdot 8 \\
3 \cdot 8\end{array}$ & $\begin{array}{l}2 \cdot 5 \\
2 \cdot 8 \\
3 \cdot 9\end{array}$ & $\begin{array}{l}2 \cdot 1 \\
2 \cdot 2 \\
2 \cdot 5\end{array}$ & $\begin{array}{l}1 \cdot 3 \\
1 \cdot 1 \\
2 \cdot 7\end{array}$ & $\begin{array}{l}0.67 \\
0.64 \\
0.78\end{array}$ & $\begin{array}{l}0.44 \\
0.49 \\
0.58\end{array}$ & $\begin{array}{l}2 \cdot 1 \\
2 \cdot 2 \\
3 \cdot 3\end{array}$ \\
\hline $\begin{array}{l}\text { Inhalation } \\
\text { (smokers } \\
\text { only) }\end{array}$ & $\begin{array}{l}\text { None } \\
\text { Slight } \\
\text { Moderate } \\
\text { Deep }\end{array}$ & $\begin{array}{l}1 \cdot 9 \\
1 \cdot 7 \\
1 \cdot 8 \\
2 \cdot 3\end{array}$ & $\begin{array}{l}1 \cdot 8 \\
2 \cdot 3 \\
2 \cdot 1 \\
2 \cdot 7\end{array}$ & $\begin{array}{l}2 \cdot 1 \\
2 \cdot 5 \\
2 \cdot 2 \\
2 \cdot 8\end{array}$ & $\begin{array}{l}2 \cdot 4 \\
3 \cdot 2 \\
2 \cdot 4 \\
1 \cdot 9\end{array}$ & $\begin{array}{l}0 \cdot 11 \\
0 \cdot 24 \\
0 \cdot 25 \\
0 \cdot 22\end{array}$ & $\begin{array}{l}0.29 \\
0.26 \\
0.27 \\
0.33\end{array}$ & $\begin{array}{l}0.36 \\
0.51 \\
0.55 \\
0.56\end{array}$ & $\begin{array}{l}1 \cdot 5 \\
0.93 \\
1.6 \\
1.8\end{array}$ & $\begin{array}{l}4 \cdot 0 \\
3 \cdot 9 \\
4 \cdot 4 \\
4 \cdot 4\end{array}$ & $\begin{array}{l}3 \cdot 1 \\
2 \cdot 9 \\
3 \cdot 0 \\
4 \cdot 1\end{array}$ & $\begin{array}{l}27 \\
2 \cdot 2 \\
2 \cdot 6 \\
3 \cdot 1\end{array}$ & $\begin{array}{r}1 \cdot 8 \\
2 \cdot 5 \\
2 \cdot 5 \\
-\end{array}$ & $\begin{array}{l}1 \cdot 9 \\
1 \cdot 8 \\
1 \cdot 7 \\
4 \cdot 7\end{array}$ & $\begin{array}{l}0 \cdot 55 \\
0.60 \\
1 \cdot 3 \\
1 \cdot 3\end{array}$ & $\begin{array}{l}0.44 \\
0.36 \\
0.56 \\
0.48\end{array}$ & $\begin{array}{l}1 \cdot 8 \\
2 \cdot 8 \\
1 \cdot 2 \\
0 \cdot 54\end{array}$ \\
\hline $\begin{array}{l}\text { Age of } \\
\text { starting } \\
\text { smoking } \\
\text { (smokers } \\
\text { only) }\end{array}$ & $\begin{array}{l}<16 \mathrm{yr} \\
16 \mathrm{yr} \\
17-18 \mathrm{yr} \\
>18 \mathrm{yr}\end{array}$ & $\begin{array}{l}2 \cdot 1 \\
1 \cdot 9 \\
1 \cdot 8 \\
2 \cdot 1\end{array}$ & $\begin{array}{l}2 \cdot 6 \\
2 \cdot 2 \\
2 \cdot 2 \\
2 \cdot 2\end{array}$ & $\begin{array}{l}3 \cdot 0 \\
2 \cdot 5 \\
2 \cdot 1 \\
2 \cdot 1\end{array}$ & $\begin{array}{l}2 \cdot 8 \\
3 \cdot 0 \\
1 \cdot 7 \\
2 \cdot 3\end{array}$ & $\begin{array}{l}0 \cdot 27 \\
0 \cdot 21 \\
0 \cdot 19 \\
0 \cdot 10\end{array}$ & $\begin{array}{l}0.33 \\
0.26 \\
0.28 \\
0.29\end{array}$ & $\begin{array}{l}0.87 \\
0.50 \\
0.53 \\
0.32\end{array}$ & $\begin{array}{l}2 \cdot 2 \\
1 \cdot 2 \\
0 \cdot 90 \\
1 \cdot 5\end{array}$ & $\begin{array}{l}4 \cdot 2 \\
4 \cdot 1 \\
1 \cdot 7 \\
4 \cdot 6\end{array}$ & $\begin{array}{l}3 \cdot 0 \\
3 \cdot 5 \\
0 \cdot 59 \\
3 \cdot 2\end{array}$ & $\begin{array}{l}2 \cdot 6 \\
2 \cdot 3 \\
0 \cdot 67 \\
2 \cdot 6\end{array}$ & $\begin{array}{l}2 \cdot 9 \\
3 \cdot 1 \\
1 \cdot 1 \\
1 \cdot 8\end{array}$ & $\begin{array}{l}1 \cdot 5 \\
1 \cdot 8 \\
4 \cdot 5 \\
2 \cdot 0\end{array}$ & $\begin{array}{l}0.63 \\
1.0 \\
2.9 \\
0.67\end{array}$ & $\begin{array}{l}0.68 \\
0.54 \\
2 \cdot 7 \\
0.42\end{array}$ & $\begin{array}{r}2 \cdot 6 \\
2 \cdot 7 \\
11 \cdot 7 \\
1 \cdot 6\end{array}$ \\
\hline \multirow[t]{2}{*}{$\begin{array}{l}\text { Type of } \\
\text { smoking } \\
\text { and } \\
\text { quantity } \\
\text { smoked }\end{array}$} & $\begin{array}{c}\text { Manufactured } \\
\text { cigarettes only } \\
<5 \text { per day. } \\
6-10 \text { per day } \\
11-15 \text { per day } \\
16-20 \text { per day } \\
>20 \text { per day }\end{array}$ & $\begin{array}{l}1 \cdot 6 \\
199 \\
1 \cdot 9 \\
2 \cdot 2 \\
2 \cdot 2\end{array}$ & $\begin{array}{l}2 \cdot 2 \\
2 \cdot 1 \\
2 \cdot 2 \\
2 \cdot 5 \\
2 \cdot 8\end{array}$ & $\begin{array}{l}2 \cdot 1 \\
2 \cdot 7 \\
2 \cdot 8 \\
2 \cdot 1 \\
2 \cdot 0\end{array}$ & $\begin{array}{l}4 \cdot 2 \\
2 \cdot 7 \\
3 \cdot 3 \\
1 \cdot 7 \\
4 \cdot 2\end{array}$ & $\begin{array}{l}0 \cdot 18 \\
0 \cdot 20 \\
0 \cdot 28 \\
0 \cdot 24 \\
0 \cdot 27\end{array}$ & $\begin{array}{l}0.25 \\
0 \cdot 29 \\
0 \cdot 28 \\
0 \cdot 31 \\
0.39\end{array}$ & $\begin{array}{l}0.87 \\
0.67 \\
0.41 \\
0.51 \\
0.50\end{array}$ & $\begin{array}{l}1 \cdot 8 \\
1 \cdot 2 \\
2 \cdot 3 \\
1 \cdot 6 \\
2 \cdot 6\end{array}$ & $\begin{array}{l}3 \cdot 9 \\
4 \cdot 1 \\
6 \cdot 2 \\
4 \cdot 8 \\
3 \cdot 0\end{array}$ & $\begin{array}{l}3 \cdot 3 \\
3 \cdot 2 \\
2 \cdot 8 \\
2 \cdot 9 \\
5 \cdot 2\end{array}$ & $\begin{array}{l}2 \cdot 9 \\
2 \cdot 5 \\
2 \cdot 6 \\
2 \cdot 0 \\
2 \cdot 7\end{array}$ & $\begin{array}{l}2 \cdot 0 \\
1 \cdot 7 \\
2 \cdot 2 \\
1 \cdot 8 \\
2 \cdot 5\end{array}$ & $\begin{array}{l}1 \cdot 2 \\
1 \cdot 3 \\
3 \cdot 0 \\
3 \cdot 4 \\
1 \cdot 5\end{array}$ & $\begin{array}{l}0.58 \\
0.67 \\
0.72 \\
0.82 \\
0.82\end{array}$ & $\begin{array}{l}0.54 \\
0.46 \\
0.26 \\
0.52 \\
0.28\end{array}$ & $\begin{array}{l}2 \cdot 3 \\
0 \cdot 92 \\
1 \cdot 6 \\
0 \cdot 84 \\
1 \cdot 1\end{array}$ \\
\hline & $\begin{array}{l}\text { Pipe only } \\
\text { Rolled } \\
\text { cigarettes only } \\
\text { All other } \\
\text { smokers }\end{array}$ & $\begin{array}{l}1 \cdot 6 \\
2 \cdot 9 \\
1 \cdot 7\end{array}$ & $\begin{array}{l}1 \cdot 7 \\
2 \cdot 4 \\
1 \cdot 8\end{array}$ & $\begin{array}{l}2 \cdot 0 \\
2 \cdot 8 \\
2 \cdot 2\end{array}$ & $\begin{array}{l}2 \cdot 2 \\
2 \cdot 5 \\
2 \cdot 1\end{array}$ & $\begin{array}{l}0 \cdot 08 \\
0 \cdot 37 \\
0 \cdot 11\end{array}$ & $\begin{array}{l}0.26 \\
0.38 \\
0.23\end{array}$ & $\begin{array}{l}0.36 \\
0.24 \\
0.23\end{array}$ & $\begin{array}{l}1.7 \\
0.40 \\
0.71\end{array}$ & & & & & & & & \\
\hline
\end{tabular}

separately in terms of age, using initially the agegrouping less than 1 year, $1-4$ years, $5-9$ years, . . . . , 75-79 years, and over 80 years. Each of these subgroups has been further divided in terms of various aspects of current smoking habits and smoking history. Comparisons have then been made between the patterns of general practice contact in groups whose personal characteristics differ solely in terms of smoking habits. For the purposes of summarizing the differences in contact pattern, which are manifested by the numbers of patients having $0,1,2 \ldots$ contacts during the survey year, it has been found that the average number of contacts provides a satisfactory single index. As the information about contacts was available in part in grouped form, the averages were obtained by calculating the mean of a statistical distribution fitted to the observed data. The negative binomial form was found to provide an adequate representation for the separate smoking categories. In order to simplify the presentation of the results the averages of the means for the five-year age-groups have been calculated for the wider age grouping corresponding to $0-14$ years, $15-29$ years, $30-44$ years, $45-59$ years, and over 59 years.

The first classification of smoking habits to be considered is in terms of the smoker, non-smoker, and ex-smoker categories. The results obtained for males and females are shown in Tables II (a) and II (b) respectively. Among males both surgery attendance and home visit rates for smokers are consistently higher than those for non-smokers in the age range between 15 and 59 years. In the above 59 years age-groups, however, the position is reversed, higher rates being recorded for nonsmokers. The results for ex-smokers show no consistent trend. The females show a pattern similar to that of males, although the excess of contacts among smokers holds for the age-groups between 15 and 44 years and the opposite trend for the over 45 age-groups.

The current smoking habits of the smokers were also classified in terms of depth of inhalation. Reference to Table II (a) shows that for males the average numbers of contacts of both types tend to be highest for the deep inhalers over the whole age range up to 59 years. In the oldest age-groups, however, the highest rates were reported for smokers who inhaled slightly. The results for females (Table II (b)) show a similar but less well-defined trend in the younger age-groups. Smoking habits were also assessed in terms of age of starting smoking and the results are included in Table II. For the most part the highest average numbers of both types of patient contact among males occur in the groups who had started smoking at age 16 years or less. The position for females is less clearly defined, partly as a result of the relatively small numbers of older patients who started smoking at age 18 years or less. The fourth subdivision of smoking habits 
TABLE III

AVERAGE NUMBERS OF HOSPITAL OUTPATIENT ATTENDANCES IN TERMS OF AGE AND SMOKING HABITS

\begin{tabular}{|c|c|c|c|c|c|c|c|c|c|c|}
\hline \multirow{2}{*}{\multicolumn{3}{|c|}{ Age-group (yr) }} & \multicolumn{4}{|c|}{ Males } & \multicolumn{4}{|c|}{ Females } \\
\hline & & & \multirow{2}{*}{$\begin{array}{l}15-29 \\
0.62 \\
0.45 \\
0.69\end{array}$} & \multirow{2}{*}{$\begin{array}{l}30-44 \\
0 \cdot 47 \\
0 \cdot 38 \\
0 \cdot 37\end{array}$} & \multirow{2}{*}{$\begin{array}{l}45-59 \\
0.52 \\
0.46 \\
0.39\end{array}$} & \multirow{2}{*}{$\begin{array}{l}>59 \\
0.46 \\
0.57 \\
0.69\end{array}$} & \multirow{2}{*}{$\begin{array}{l}15-29 \\
0.56 \\
0.46 \\
0.56\end{array}$} & \multirow{2}{*}{$\begin{array}{l}30-44 \\
0.51 \\
0.45 \\
0.44\end{array}$} & \multirow{2}{*}{$\begin{array}{l}45.59 \\
0.48 \\
0.52 \\
0.73\end{array}$} & \multirow{2}{*}{$\begin{array}{l}>59 \\
0.47 \\
0.59 \\
0.57\end{array}$} \\
\hline All patients & $\begin{array}{l}\text { Smokers } \\
\text { Non-smokers } \\
\text { Ex-smokers }\end{array}$ & & & & & & & & & \\
\hline $\begin{array}{l}\text { Inhalation } \\
\text { (smokers } \\
\text { only) }\end{array}$ & $\begin{array}{l}\text { None ... } \\
\text { Slight ... } \\
\text { Moderate } \\
\text { Deep .. }\end{array}$ & & $\begin{array}{l}0.55 \\
0.52 \\
0.74 \\
0.08\end{array}$ & $\begin{array}{l}0.32 \\
0.49 \\
0.49 \\
0.04\end{array}$ & $\begin{array}{l}0.55 \\
0.51 \\
0.53 \\
0.05\end{array}$ & $\begin{array}{l}0.41 \\
0.50 \\
0.48 \\
0.20\end{array}$ & $\begin{array}{l}0.63 \\
0.48 \\
0.51 \\
0.72\end{array}$ & $\begin{array}{l}0.49 \\
0.40 \\
0.58 \\
0.70\end{array}$ & $\begin{array}{l}0.48 \\
0.48 \\
0.57 \\
0.50\end{array}$ & $\begin{array}{r}0.34 \\
0.44 \\
0.49 \\
-\end{array}$ \\
\hline $\begin{array}{l}\text { Age of } \\
\text { starting } \\
\text { smoking } \\
\text { (smokers } \\
\text { only) }\end{array}$ & $\begin{array}{l}>16 \mathrm{yr} \\
16 \mathrm{yr} \ldots \\
17-18 \mathrm{yr} \\
<18 \mathrm{yr}\end{array}$ & $\begin{array}{l}\cdots \\
\cdots \\
\cdots\end{array}$ & $\begin{array}{l}0.86 \\
0.60 \\
0.52 \\
0.69\end{array}$ & $\begin{array}{l}0.56 \\
0.50 \\
0.41 \\
0.50\end{array}$ & $\begin{array}{l}0.76 \\
0.53 \\
0.46 \\
0.56\end{array}$ & $\begin{array}{l}0.53 \\
0.54 \\
0.38 \\
0.49\end{array}$ & $\begin{array}{l}0.58 \\
0.57 \\
0.55 \\
0.48\end{array}$ & $\begin{array}{l}0.58 \\
0.56 \\
0.46 \\
0.51\end{array}$ & $\begin{array}{l}0.36 \\
0.61 \\
0.52 \\
0.49\end{array}$ & $\begin{array}{l}0 . \overline{39} \\
0.41 \\
0.41\end{array}$ \\
\hline \multirow[t]{2}{*}{$\begin{array}{l}\text { Type of } \\
\text { smoking and } \\
\text { quantity } \\
\text { smoked }\end{array}$} & 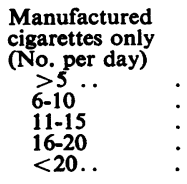 & $\begin{array}{l}\cdots \\
\cdots \\
\cdots \\
\cdots\end{array}$ & $\begin{array}{l}0.53 \\
0.58 \\
0.72 \\
0.98 \\
0.68\end{array}$ & $\begin{array}{l}0.49 \\
0.48 \\
0.51 \\
0.40 \\
0.64\end{array}$ & $\begin{array}{l}0.61 \\
0.61 \\
0.61 \\
0.42 \\
0.37\end{array}$ & $\begin{array}{l}0.38 \\
0.43 \\
0.70 \\
0.43 \\
0.26\end{array}$ & $\begin{array}{l}0.52 \\
0.49 \\
0.78 \\
0.64 \\
-\end{array}$ & $\begin{array}{l}0.45 \\
0.51 \\
0.61 \\
0.57 \\
-\end{array}$ & $\begin{array}{l}0.56 \\
0.53 \\
0.42 \\
0.46 \\
-\end{array}$ & $\begin{array}{r}0.39 \\
0 \quad 36 \\
0.63 \\
0.39 \\
\end{array}$ \\
\hline & $\begin{array}{l}\text { Pipe only } \\
\text { Rolled cigarettes } \\
\text { only .. } \\
\text { All other smokers }\end{array}$ & & $\begin{array}{l}0.47 \\
0 . \overline{63}\end{array}$ & $\begin{array}{l}0.40 \\
0.49 \\
0.52\end{array}$ & $\begin{array}{l}0.63 \\
0.61 \\
0.44\end{array}$ & $\begin{array}{l}0.43 \\
0.44 \\
0.40\end{array}$ & $\begin{array}{l}- \\
-\end{array}$ & $\begin{array}{l}- \\
-\end{array}$ & $\begin{array}{l}- \\
-\end{array}$ & - \\
\hline
\end{tabular}

examined in this analysis was in terms of type of smoking, a distinction being made for males between those smoking manufactured cigarettes only, pipe only, rolled cigarettes only, and all other smokers. The results for cigarette smokers were further subdivided in terms of current consumption. Virtually all female smokers consumed manufactured cigarettes only, and insufficient data were available for the other categories to permit a worthwhile analysis. Among the younger males, the highest contact rates in the group smoking manufactured cigarettes only were reported for those with the highest consumption of cigarettes. Above the age of 44 years, however, the cigarette smokers with the more moderate levels of consumption tend to have the higher average numbers of contacts. The contact rates for males smoking a pipe only are on the whole rather lower than for smokers generally, while those for the group smoking rolled cigarettes only tend to be rather higher. The data for female cigarette smokers show no consistent pattern.

The information collected on the census included a wide range of personal characteristics, including social class, marital status, age of finishing full-time education, family size, and household size, as well as smoking habits. The data were therefore subdivided in terms of each characteristic, as well as in terms of smoking habits, and mean patient contact rates were calculated for each subgroup. In general, the same trends were present in the separate subgroups as in the combined data.
In order to assess the diagnostic structure of the $\vec{\varphi}$ patient contacts, each diagnosis was coded in terrim of the ICD broad diagnostic categories and the average numbers of contacts involving each diagnos tic category were calculated. In males the average surgery attendance rates were appreciably higher among smokers than non-smokers for ICD cate- $\stackrel{\circ}{\perp}$ gories II (neoplasms), VI (nervous diseases, sense $\stackrel{\varrho}{\Rightarrow}$ organs), VIII (respiratory), IX (digestive), $\mathrm{X}$ 웅 (genito-urinary), and XVII (accidents). The reverse trend was present for categories I (infective and parasitic) and III (allergy). In females the major difference was an excess of attendances for cate- $\overparen{\overparen{D}}$ gories V (mental, psychological), VIII (respiratory), ? $\mathrm{X}$ (genito-urinary), and XVI (symptoms, senility). The results for home visits are less clear-cut than those for surgery attendances, and for many of the $\frac{O}{3}$ subgroups the numbers with particular diagnostic categories are too small to permit any worthwhile 음 analysis. However, there was an excess of home $\rightarrow$ visits for smokers as compared with non-smokers for categories V (mental, psychological), VII (circulation), and XVII (accidents) among males.

\section{Hospital Contacts}

The patient contacts with the local hospitalo service may be divided into two types-outpatient $\frac{}{\Phi}$ and inpatient. The average numbers of outpatient $\stackrel{\oplus}{+}$ contacts are summarized in terms of age and 0 smoking habits in Table III, which is set out in a $\frac{\vec{\Phi}}{\vec{D}}$ 
TABLE IV

AVERAGE NUMBER OF DAYS SPENT IN HOSPITAL DURING THE SURVEY YEAR (ALL SPELLS) IN TERMS OF AGE AND SMOKING HABITS

\begin{tabular}{|c|c|c|c|c|c|c|c|c|c|c|}
\hline \multirow{2}{*}{\multicolumn{3}{|c|}{ Age-group (yr) }} & \multicolumn{4}{|c|}{ (a) Males } & \multicolumn{4}{|c|}{ (b) Females } \\
\hline & & & $15-29$ & $30-44$ & $45-59$ & $60+$ & $15-29$ & $30-44$ & 45-59 & $60+$ \\
\hline \multirow{2}{*}{$\begin{array}{l}\text { All patients } \\
\text { Inhalation } \\
\text { (smokers only) }\end{array}$} & \multicolumn{2}{|c|}{$\begin{array}{l}\text { Smokers } \ldots \\
\text { Non-smokers } \\
\text { Ex-smokers }\end{array}$} & $\begin{array}{l}1.0 \\
0.4 \\
1.0\end{array}$ & $\begin{array}{l}0.9 \\
0.8 \\
0.2\end{array}$ & $\begin{array}{l}0.8 \\
0.6 \\
0.4\end{array}$ & $\begin{array}{l}1 \cdot 0 \\
0 \cdot 7 \\
1 \cdot 4\end{array}$ & $\begin{array}{l}1 \cdot 8 \\
1.2 \\
1.7\end{array}$ & $\begin{array}{l}1.2 \\
1.1 \\
1.0\end{array}$ & $\begin{array}{l}0.9 \\
0.8 \\
1.9\end{array}$ & $\begin{array}{l}1.2 \\
1.5 \\
1.5\end{array}$ \\
\hline & \begin{tabular}{|l|} 
None \\
Slight \\
Moderate \\
Deep \\
\end{tabular} & $\begin{array}{ll}\because & \because \\
\because & \because \\
\because & \because \\
\end{array}$ & $\begin{array}{l}0 \cdot 2 \\
0 \cdot 5 \\
1 \cdot 1 \\
2 \cdot 1 \\
\end{array}$ & $\begin{array}{l}0.1 \\
0.5 \\
1.1 \\
1.3 \\
\end{array}$ & $\begin{array}{l}0.5 \\
0.8 \\
0.8 \\
1.1 \\
\end{array}$ & $\begin{array}{l}0.6 \\
0.6 \\
11.4 \\
2.3 \\
\end{array}$ & $\begin{array}{l}1.4 \\
1.8 \\
1.8 \\
2.8 \\
\end{array}$ & $\begin{array}{l}0.9 \\
1.2 \\
1.3 \\
1.4 \\
\end{array}$ & $\begin{array}{l}0.9 \\
1.3 \\
0.8 \\
0.2 \\
\end{array}$ & $\begin{array}{l}1.1 \\
1.6 \\
0.7 \\
1.3\end{array}$ \\
\hline $\begin{array}{l}\text { Age of starting } \\
\text { smooking (smokers } \\
\text { only) }\end{array}$ & $\begin{array}{l}<16 \mathrm{yr} \\
16-18 \mathrm{yr} \\
>18 \mathrm{yr}\end{array}$ & $\begin{array}{l}. \\
\because .\end{array}$ & $\begin{array}{l}0.8 \\
1.4 \\
0.1\end{array}$ & $\begin{array}{l}1.2 \\
0.9 \\
1.1\end{array}$ & $\begin{array}{l}1.8 \\
0.6 \\
0.5\end{array}$ & $\begin{array}{l}1.4 \\
0.8 \\
0.9\end{array}$ & $\begin{array}{l}1 \cdot 5 \\
2 \cdot 0 \\
2.0\end{array}$ & $\begin{array}{l}1.0 \\
1.1 \\
1.5\end{array}$ & $\begin{array}{l}0.8 \\
0.9 \\
0.9\end{array}$ & $\begin{array}{l}0.6 \\
0.9 \\
0.9\end{array}$ \\
\hline \multirow[t]{2}{*}{$\begin{array}{l}\text { Type of smoking } \\
\text { and quantity } \\
\text { smoked }\end{array}$} & \multicolumn{2}{|c|}{ 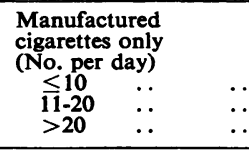 } & $\begin{array}{l}0.4 \\
1.3 \\
0.7\end{array}$ & $\begin{array}{l}0 \cdot 9 \\
1 \cdot 1 \\
0 \cdot 3\end{array}$ & $\begin{array}{l}1.0 \\
0.9 \\
0.5\end{array}$ & $\begin{array}{l}0.9 \\
1.7 \\
1.7\end{array}$ & $\begin{array}{l}1.6 \\
2.5 \\
1.8\end{array}$ & $\begin{array}{l}1.3 \\
0.9 \\
1.0\end{array}$ & $\begin{array}{l}1.0 \\
0.8 \\
0.9\end{array}$ & $\begin{array}{l}1 \cdot 3 \\
1 \cdot 1 \\
1 \cdot 1\end{array}$ \\
\hline & \multicolumn{2}{|c|}{ 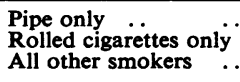 } & 1.1 & $\begin{array}{l}0.4 \\
二\end{array}$ & $\begin{array}{l}0.4 \\
0.6 \\
0.6\end{array}$ & $\frac{0 \cdot 7}{0.4}$ & & & & \\
\hline
\end{tabular}

similar form to Table II. For both males and females, the average contact rates among smokers tend to be higher than those for non-smokers below 45 years and lower above 60 years of age. The contact rates for males who started smoking at less than 16 years of age tend to be higher than for the remaining smokers, but for females the relationship is less clear cut.

The hospital inpatient contacts have been analysed in terms of the average numbers of days spent in hospital during the survey year for the various age and smoking categories. The results are summarized in Table IV, which refers to the total of all spells of inpatient stay. Because of the relatively small numbers of admissions, the subdivision of smoking habits used in this Table has been broadened in comparison with the corresponding tables for general practice and hospital outpatient contacts. Among males the average period spent in hospital by the non-smokers is considerably less than that spent by the smokers in three of the four broad age-groups. A similar pattern exists among females, although the differences between the smokers and non-smokers are smaller. The average periods spent in hospital by male smokers of all ages and by female smokers of less than 45 years of age tend to increase with increasing depth of inhalation, the differences between the extremes of the spectrum of inhalation being very marked. In terms of age of starting smoking, the results for males of more than 29 years of age show a tendency for the highest numbers of days spent in hospital to occur for the group who started smoking at less than 16 years of age.

Much of the inpatient stay of both males and females is associated with mental and psychiatric disorders. If all spells of inpatient stay for which a diagnosis belonging to ICD broad diagnostic category V (mental and psychological disorders) was recorded are excluded, the results for males show a similar pattern in terms of smoking habits to the total for all inpatient spells. A further large component of the female inpatient stay in the 15-45 years age-group is associated with child-bearing, and in the 15-29 years age-group average periods of inpatient stay of $1.0,0.2$, and 1.5 days were attributed to childbirth for smokers, non-smokers, and ex-smokers respectively. Among females there were no consistent differences in terms of smoking habits in the average length of stay associated with nervous and psychiatric disorders, and if the latter and childbirth are excluded the pattern is similar to that for all spells.

The average numbers of outpatient contacts attributed to each of the broad ICD categories were also calculated. For males the most important category in numerical terms is XVII (accidents) and the contact rates for smokers are considerably higher than for non-smokers in the three age-groups below 60 years. Because of the relatively small numbers of hospital admissions in the various smoking groups, a separate analysis of average length of hospital inpatient stay in terms of diagnostic category was not considered worthwhile. 
However, the proportions of female smokers admitted in categories II (neoplasm), X (genitourinary), and XI (childbirth) were consistently higher than the corresponding proportions of female non-smokers of the same age. On the other hand, the reverse trend applies for males assigned to category III (allergy).

The average numbers of outpatient consultations were also analysed in terms of smoking habits and social class. The contrasts between smokers and nonsmokers noted in the overall data are present only weakly for the separate social classes. It should also be emphasized that female non-smokers of more than $\mathbf{4 5}$ years of age consistently use the outpatient facilities more than smokers in every social class. It was not considered worthwhile to subdivide the inpatient data in a similar way, but the tendency for smokers to use the inpatient services more than nonsmokers was present to some extent for all the social class groups.

\section{COMMENT}

The present study is based upon an enquiry into the usage of the health services by a large general population. Because of the objectives and scale of the survey, the information collected was limited to a brief record of each patient contact and was not specifically directed towards the assessment of the effects of smoking habits. Nor did the census from which the personal characteristics of the population were established give any special emphasis to information about smoking habits. While a study specially designed to investigate the relationships between smoking and morbidity might have permitted the testing of specific hypotheses, this more generalized enquiry has the important advantage that each of the wide variety of environmental and social factors which may have a bearing on the health of a large population was given equal weight. Thus, although the methodology can be regarded as being imprecise in comparison with what is possible using special survey techniques, the results are specially valuable in that they reflect the behaviour of a large and general population in their day-to-day contacts with the National Health Service.

Although private medical care was excluded from the study, this factor is unlikely to have affected the general practice results to any appreciable extent. On the other hand, private consultations with hospital doctors are more common, although probably only a small proportion of the total, even in the higher social classes. Thus, in spite of the difficulties associated with the definition of the population at risk in terms of the NHS general practice lists and the particular form of enquiry, there is no reason to suppose that any bias has been introduced when individuals with different smoking habits are compared.

A clear distinction must also be made between ill health and the use of health service resources. The reasons why a person decides to seek medical care are known to be highly complex. Even with a free and universal health care system, the expectations of the patient about the help he is likely to receive and the inconvenience of obtaining access to care will be weighed against the distress, present or future, to which he is or may be subject. It is doubtful whether these factors would operate in the same way among people with different smoking habits. Given the present state of knowledge, it might be argued that any person who is prepared to smoke cigarettes is, by definition, irresponsible about his health and therefore less likely to seek care when such care is necessary. The well-documented attitude of smokers to common symptoms such as 'smokers' cough' reinforces this view. On this basis, the usage of health services resources by smokers probably underestimates their morbidity, as opposed to the corresponding data for non-smokers. Different types of health services usage will, of course, be affected in different ways? The most common form of contact, the generas practice surgery attendance, depends to the greatest. extent upon the motivation of the patient (as opposed to the doctor) and is likely to be influenced most. On the other hand, hospital inpatient stay, while conditioned to a considerable extent by medical advice, also reflects the circumstances of the patient. Because smoking can be an expensive habit, smokers may be presumed to have a smaller disposable income than non-smokers and may therefore be less able to provide for themselves when home care is an alternative to admission to hospital as an inpatient.

When the possible existence of a causal relation between smoking habits and health is considered, the much discussed difficulties about the reasons for taking up and continuing smoking, for inhaling deeply, or for smoking cigarettes as opposed to cigars cannot be ignored. In a survey of health services usage the problem is particularly acute, as at least during the past 10 years few patients who have consulted a doctor for any condition which might remotely be considered attributable to or affected by smoking can have avoided a very forceful presentation of the arguments for giving up or moderating the habit. The relatively high proportion of female ex-smokers known to have consulted a doctor for reasons connected with maternity care noted in the present study provides confirmatory 
evidence. For this reason, it may be expected that some smokers who have made contact with the health care system may thereby have been persuaded to reduce or modify their smoking habits or even to transfer to the ex-smoker category. The effect of any such tendency will be to lead to a lower usage of health services among the group classed as smokers and among the smokers who inhale deeply and have a relatively high consumption of cigarettes.

It must also be borne in mind that the population living in a district at any particular time are the survivors of a larger group who have not so far died or moved away. The differences between the death rates of smokers and non-smokers are well established and the proportions of males alive at age 15 years who may be expected to reach any given age are lower in smokers than in non-smokers (Hammond, 1966). These data refer to a population living in the United States rather than in Great Britain, but the results indicate at least the order of magnitude of the differences in the mortality experience of smokers and non-smokers which might be expected in the population studied. The differential effect of selection by death in smokers and non-smokers is very marked above the age of 60 years. For example, the proportion of smokers alive at age 15 years who die before reaching the age of 70 years is over $70 \%$, compared with about $40 \%$ of non-smokers. Thus, the removal by death of a higher proportion of smokers than non-smokers in the older age-groups may lead to an underestimate of any effect of smoking on health in this part of the populacion.

For both types of general practice contact and for hospital outpatient contacts, the data recorded for male smokers and non-smokers show consistent differences. Up to about 60 years of age the average contact rates for smokers are consistently higher than those for non-smokers. The differences are substantial, and typically of the order of a quarter of the rate for non-smokers. Above the age of about 60 years, however, the situation is reversed, nonsmokers tending to have higher contact rates than smokers. As indicated above, an appropriate correction for the differential survival rates in terms of smoking habits is likely to produce an excess of contacts among smokers for the whole of the range of ages. The transfer of older smokers to the exsmoker category as a result of medical advice or because of their inability to meet the costs of the habit after retirement from full-time employment may also tend to obscure the effect of smoking in the older age-groups. In terms of hospital inpatients, the smokers have in general longer average length of stay than the non-smokers, the difference when taken over all age-groups being about 0.25 day per person per year. The average length of inpatient stay of smokers above the age of 59 years is 1.0 day, in comparison with 1.4 day for ex-smokers and 0.7 day for non-smokers. In general, therefore, it appears that for males the usage of health services resources by smokers is consistently higher than that by non-smokers.

The results for females show similar but rather less well-defined trends in terms of the differences between smokers and non-smokers, possibly because the smoking habit is less prevalent and in smokers less intense than in males. There was an excess of usage of resources by female smokers as compared with non-smokers up to the age of about 45 years, and an excess of usage by non-smokers above that age. The average numbers of patient contacts by ex-smokers tend to be higher than by either smokers or non-smokers which suggests that females are perhaps more ready to accept medical and other advice to give up the habit than males. The considerable excess of usage among smokers and ex-smokers associated with maternity is particularly interesting, and suggests that smokers are more fertile than non-smokers.

There were also consistent differences in the usage of different resources among male smokers in terms of depth of inhalation. The average numbers of patient contacts among the males of up to about 55 years of age tend to increase with increasing depth of inhalation. The wide variations in average length of stay in hospital are particularly striking, the figures for the various age-groups for smokers who inhale deeply being between 2.5 and 10 times greater than those for smokers who do not inhale at all. The differences in terms of age of starting smoking are less marked, although the group who started smoking at the youngest age are normally at the greatest disadvantage. Current smoking habits among males smoking cigarettes only do not appear to bear any consistent relationship to contact rates, although the results suggest that pipe smokers are at an advantage and smokers of rolled cigarettes are at a disadvantage in comparison with the former group. Females exhibit similar although less well-defined trends.

Although a study of personal characteristics shows marked variations of smoking habits in terms of factors such as social class, the trends noted in the overall data were for the most part present among particular and more homogeneous subgroups. This tends to rule out the possibility that the observed variations of patient contact rates with smoking habits are the result of a fortuitous association of smoking habits with other personal 
characteristics. The differences in the diagnostic content of the health services usage by smokers and non-smokers are interesting. Higher contact rates among smokers were reported for neoplasms, diseases of the nervous system, the sense organs, the respiratory system, the genito-urinary system, and the digestive system, but the difference was particularly pronounced for accidents. Many of these accidents took place on the roads or at home and it is a matter for speculation whether a substantial proportion were the result of the distractions associated with the smoking habit rather than with an association between 'accident proneness' and a tendency to smoke. It is also interesting that higher contact rates were reported for non-smokers than for smokers for the ICD broad diagnostic categories covering infectious and parasitic disease and allergies.

In a survey of the type described, in which individual smoking habits are not subject to experimental control and may well be related to medical advice, it is impossible to measure the influence of smoking with absolute certainty. On balance the most plausible explanation of the results obtained is that smoking leads to a deterioration of the health of those who indulge in the habit; the earlier the age of starting and the greater the depth of inhalation, the greater the effect. This observation is consistent with the results of surveys of health carried out by the interview technique when expressed in terms of activity-limiting chronic conditions (State of California Department of Public Health, 1957), and also when expressed in terms of days off work (State of California Department of Public Health, 1955), and with the results of special surveys of particular conditions carried out in many countries as described in Smoking and Health Now by the Royal College of Physicians (1971). However, some of the differences between smokers and nonsmokers, for example in terms of neurotic illness, may be an expression of some common underlying characteristic of the individuals concerned. The results of the present survey are valuable in that they provide quantitative information about variations in the demands on the health care system between groups with different smoking experience. Because of the higher death rates among smokers and the uncertainties about the precise way in which difficulties of access limit patient contacts in the NHS, it is not possible to estimate the precise effects of any possible future changes in smoking habits.

\section{SUMMARY}

This paper is concerned with the use made of the general practice and hospital services during a 12-month period in 1966-67 by some 32,000 males and females living in the City of Exeter. The com- $\frac{8}{3}$ position of the survey population was found to be $\frac{\mathbb{\Phi}}{\mathbb{Q}}$ similar to that of the population of the City as a whole. The recorded smoking habits were broadly $\overrightarrow{\vec{D}}$ in agreement with other surveys carried out in England $\frac{7}{0}$ and Wales at about the same time. The use of the $\frac{C}{\partial}$ general practice service was considered in terms of $\frac{\bar{\sigma}}{\bar{s}}$ the average annual numbers of surgery attendances $\overparen{\nabla}$ and home visits. Among males, both types of usage tended to be higher in smokers than in non-smokers ${ }^{\circ}$ up to the age of about 60 years, but lower in smokers $\overrightarrow{0}$ than in non-smokers in the oldest age-groups. $\vec{\overrightarrow{ }}$ Contact rates among the younger smokers tended $\underset{\sigma}{\omega}$ to increase with increasing depth of inhalation, with $\frac{\widehat{\sigma}}{0}$ increasing consumption of tobacco, and with $\stackrel{\odot}{\supset}$ decreasing age of starting smoking. In general, similar but less clearly defined trends were noted for females, although the age at which the relative $\infty$ position of smokers and non-smokers was reversed 을 was somewhat lower than in males. The data were subdivided in terms of personal characteristics, $\mathbb{D}$ including social class, marital status, age of finishing full-time education, family size, and household ฏ size. For the most part the trends noted in the combined data persisted in these more hom\& $\overrightarrow{0}$ geneous subgroups of the population. The diagnost structure of the patient contacts was examined. A excess of usage by smokers was noted for neơ plasms, nervous diseases, and diseases of the sense organs, diseases of the respiratory, digestive, and genito-urinary systems, and accidents, the last $\mathbb{D}$ category being by far the most important. The reverse trend was noted for infectious and parasitic $\frac{O}{3}$ diseases and allergy. The hospital contacts were $\vec{J}$ analysed in terms of the numbers of outpatient appointments and inpatient admissions and the length of inpatient stay. For both males and females, $\stackrel{\mathbb{D}}{\stackrel{\circ}{O}}$ the average number of outpatient contacts was? higher among smokers than non-smokers for ages 3 up to about 45 years and lower in the age-groups above 60 years. The usage of inpatient resources $\frac{\rho}{3}$ showed a considerable excess among smokers throughout almost the whole of the age range. There were also very marked differences in inpatient $\frac{D}{0}$ usage in terms of inhalation, the average period of hospital inpatient stay (all spells) increasing very $\sigma$ markedly with increasing depth. The trends in $N$ hospital usage were present when the results were $\underset{\omega}{N}$ subdivided in terms of other personal characteristics. Similar trends in terms of diagnostic structure were observed to those for general practice contacts. $\frac{\overparen{D}}{\Phi}$ The significance of the observed results is discussed. $\stackrel{\oplus}{+}$ It is concluded that the smoking habit is associated 0 with a progressive deterioration of health, which is 
reflected in increased usage of health services resources.

This study was part of the Exeter Community Health Research Project and the basic data were recorded by a large group of general practitioners and hospital doctors. The data were collected, processed, and analysed by the staff of the Institute of Biometry and Community Medicine of the University of Exeter. I am obliged to both groups for their help and support.

\section{REFERENCES}

AshroRd, J. R., Brown, S., Morgan, D. C., and RaE, S. (1968). The pulmonary ventilatory function of coal miners in the United Kingdom. Amer. Rev. resp. Dis., 97, 810 .

-, Morgan, D. C., Rae, S., and Sowden, R. R. (1970). Respiratory symptoms in British coal miners. Amer. Rev. resn. Dis., 102, 370.

--, and Pearson, N. G. (1970). Who uses the health services and why? J. roy. Statist. Soc., A, 133, Part 3, 295.
HAMmoND, E. C. (1966). Smoking in relation to the death rates of one million men and women. Nat. Cancer Inst. Monogr., 19, 127.

Medical Research Council (1961). (Committee on the Aetiology of Chronic Bronchitis) Instructions for the Use of the Short Questionnaire on Respiratory Symptoms, 1960. London.

Royal College of Physicians (1971). Smoking and Health Now. Pitman Medical and Scientific Publishing Co., London.

State of California Department of Public Health (1955). California Health Survey (unpublished). (1957). Health in California.

ToDD, G. F. (1966). Reliability of statements about smoking habits. Supplementary report. Tobacco Research Council, Research Paper 2A. London.

World Health Organization (1957). Manual of the International Classification of Diseases, Injuries, and Causes of Death, 7th ed. W.H.O., Geneva. 